\title{
Empirical comparison of single nucleotide polymorphisms and microsatellites for population and demographic analyses of bowhead whales
}

\author{
Phillip A. Morin ${ }^{1, *}$, Frederick I. Archer ${ }^{1}$, Victoria L. Pease ${ }^{1}$, \\ Brittany L. Hancock-Hanser ${ }^{1}$, Kelly M. Robertson ${ }^{1}$, Ryan M. Huebinger ${ }^{2,5}$, Karen K. \\ Martien $^{1}$, John W. Bickham ${ }^{2,6}$, J. Craig George ${ }^{3}$, Lianne D. Postma ${ }^{4}$, Barbara L. Taylor ${ }^{1}$ \\ ${ }^{1}$ Protected Resources Division, Southwest Fisheries Science Center, National Marine Fisheries Service, \\ National Oceanic and Atmospheric Administration, 8901 La Jolla Shores Drive, La Jolla, California 92037, USA \\ ${ }^{2}$ Department of Forestry and Natural Resources, Purdue University, 715 West State St., West Lafayette, Indiana 47907-2061, USA \\ ${ }^{3}$ North Slope Borough Department of Wildlife Management, PO Box 69, Barrow, Alaska 99723, USA \\ ${ }^{4}$ Fisheries and Oceans Canada, Central and Arctic Region, 501 University Cr., Winnipeg, Manitoba R3T 2N6, Canada \\ ${ }^{5}$ Present address: University of Texas Southwestern Medical Center, 5323 Harry Hines Blvd, Dallas, Texas 75390-9160, USA \\ ${ }^{6}$ Present address: Battelle Memorial Institute, 10777 Westheimer, Suite 1105, Houston, Texas 77042, USA
}

\begin{abstract}
Interest in bowhead whale stock structure has been high due to the species' extreme historical depletion, differential rates of recovery, the potential effects of climate change, and the need to set appropriate quotas for aboriginal hunts. We present an analysis of 42 linked and unlinked single nucleotide polymorphisms (SNPs) among 3 bowhead whale stocks and within the Bering/Chukchi/Beaufort Seas (BCB) stock, and compare results with previously published results of mtDNA control region sequences and 22 microsatellites. We performed tests of population structure $\left(F_{\mathrm{ST}}, \chi^{2}, \mathrm{STRUCTURE}\right)$, population assignment, and estimates of effective population size $\left(N_{\mathrm{e}}\right)$, and evaluated different numbers of loci and samples to estimate the relative statistical power of SNPs and microsatellites. Results indicate that this number of SNPs provides similar power to microsatellites to detect low levels of differentiation $\left(F_{\mathrm{ST}}=0.005-0.03\right)$ between bowhead populations with sample sizes of at least 20 per population. Neither marker performed well for Bayesian analysis of population structure (STRUCTURE) for the strata that had high diversity coupled with low differentiation. This example is valuable in cautioning against use of STRUCTURE to exclude demographic independence of relatively abundant populations. Microsatellites provided greater precision for estimates of $N_{\mathrm{e}}$ and for assignment tests. All 3 genetic marker types are consistent with the BCB stock being a single population. For microsatellites, differences were found between individuals born before 1949 and those born after 1979. SNPs are continuing to prove valuable as tools for understanding structure and demography of populations, and are likely to prove beneficial for long-term monitoring of bowhead whales.
\end{abstract}

KEY WORDS: Population structure - SNP - Cetacean - Population genetics - Genetic marker • Conservation management $\cdot$ Balaena mysticetus

\section{INTRODUCTION}

Population genetic analyses using microsatellite loci have been widely applied to studies of population differentiation at levels ranging from low-level population subdivision to phylogeography and taxonomy. Further analyses of demographic parameters have included estimation of effective population size $\left(N_{\mathrm{e}}\right)$, detection of migration (e.g. assignment tests), and inference of recent bottlenecks. Single nucleo- 
tide polymorphism (SNP) genotyping is slowly growing in popularity for population genetics and molecular ecology (Brumfield et al. 2003, Morin et al. 2004, Seddon et al. 2005, Seeb et al. 2011), but it remains to be seen how appropriate SNPs are for some applications. Despite some significant benefits to using SNPs (e.g. large number of SNPs in most genomes, ease and efficiency of genotyping, simple and low mutation rate; reviewed in Morin et al. 2004, Helyar et al. 2011), there are questions about whether they provide sufficient statistical power to detect low levels of population structure (e.g. for demographically independent populations with $N_{\mathrm{e}} m \geq 1$, where $N_{\mathrm{e}}$ is the effective population size and $m$ is the migration rate per generation; Wright 1931) without using hundreds or thousands of SNPs. Additionally, their appropriateness for estimating demographic parameters has not been fully evaluated.

We previously evaluated the statistical power for detecting population structure based on simulated data (Morin et al. 2009c), and there is a small but rapidly growing number of empirical studies of population structure using SNPs (e.g. Berlin et al. 2008, Narum et al. 2008, Hefti-Gautschi et al. 2009, Amend et al. 2010, Keller et al. 2010, Mims et al. 2010, Quintela et al. 2010, Freamo et al. 2011, Mesnick et al. 2011). For non-model organisms, there are still few empirical studies that directly compare the utility or power of SNPs relative to microsatellites for detecting population structure (Narum et al. 2008, Smith \& Seeb 2008, Coates et al. 2009, Glover et al. 2010, Hess et al. 2011). Previous comparisons of SNPs and microsatellites have typically been limited to 1 or 2 types of analysis (e.g. assignment and population structure; Narum et al. 2008, Smith \& Seeb 2008, Glover et al. 2010) and have included at least some ascertainment bias (intentional or due to application of markers ascertained in 1 population). These studies have taken place on commercially important salmonids, with the goal of finding an optimal set of loci that can assign individuals in a mixed-stock analysis to known populations of origin. There remains a need for comparison of the use of SNPs versus microsatellites to detect lowlevel population structure with a set of broadly ascertained and unbiased SNPs, to assign individuals to populations using commonly used methods, and to estimate demographic parameters such as $N_{\mathrm{e}}$.

Here we present a comparative analysis of 22 microsatellites and 42 SNPs for power to detect low levels of genetic structuring in the bowhead whale Balaena mysticetus. We further evaluate the strengths and limitations of microsatellites and SNPs for a variety of population and demographic analyses, includ- ing estimation of $N_{\mathrm{e}}$, assignment tests, and estimation of the number of populations using STRUCTURE (Pritchard et al. 2000, Falush et al. 2003, Hubisz et al. 2009). Finally, we use random resampling of the SNP and microsatellite data sets and population sample sets to estimate the relative power of different numbers of each marker type to detect population structure at the low levels observed between bowhead whale populations, and to test the effect of varying sample sizes on statistical power. The populations included in our study represent 2 common situations: comparison of large and similarly sized populations, and comparison of large and small populations, where the effects of drift are expected to be different, and the proportions of sampled individuals relative to the population size are also very different.

Bowhead whales are the longest-lived large baleen whale species, with populations found historically throughout the Arctic in waters adjacent to the sea ice edge and in polynyas (persistent areas of open water within the pack ice). They are known to migrate large distances, even through areas covered with $>90 \%$ sea ice (Krutzikowsky \& Mate 2000). Population ranges likely have expanded and contracted across the Canadian Arctic during periods of warmer and cooler climate (McLeod et al. 1993, Dyke et al. 1996), and currently isolated populations in the Bering/Chukchi/Beaufort Seas (BCB) and the eastern Canadian archipelagos have likely experienced gene flow multiple times over the last approximately 10500 yr. Strong fidelity to feeding and breeding grounds also likely played a role in limiting mixing of populations within and between northern seas (Finley 2001, Rugh et al. 2003). Bowheads were commercially hunted from the 18th century in the North Atlantic and the 19th century in the North Pacific. By 1918, bowhead whales were commercially extinct, and as few as 1000 individuals ( $\leq 10 \%$ of original populations) may have remained in each region (Burns et al. 1993, Rugh et al. 2003, Brandon \& Wade 2006).

Four bowhead stocks are currently recognized by the International Whaling Commission for management purposes, and are assumed to correspond to demographically independent populations. In the North Pacific, the largest stock is the BCB stock, with wintering grounds in the Bering Sea and summer feeding grounds in the Chukchi and Beaufort Seas. The current population size is estimated at 10000 to 13000 , and the historical population size has been estimated between approximately 14000 and 30000 (Burns et al. 1993, Rugh et al. 2003, George et al. 2004, Brandon \& Wade 2006). In the western North Pacific, a small summer feeding population of a few 
hundred whales is isolated in the Sea of Okhotsk (SO), with no indication of ongoing gene flow with the BCB stock and unknown wintering grounds (Rugh et al. 2003, LeDuc et al. 2005). In the North Atlantic, 3 stocks were historically recognized, but recent studies have suggested that the Davis Strait and Hudson Bay populations of eastern Canada and Greenland are actually one population (henceforth referred to as Eastern Canada [EC]), separate from the Spitsbergen stock in the eastern North Atlantic (Heide-Jørgensen et al. 2006b). The Spitsbergen stock was most likely the largest bowhead population prior to commercial whaling, but was reduced to probably fewer than 300 animals and has not shown signs of recovery; it may currently number only in the tens of individuals (reviewed in Rugh et al. 2003). The EC stock probably numbered close to 12000 prior to commercial whaling and is now estimated at approximately 8000 (Heide-Jørgensen et al. 2006a).

Interest in the genetic composition of bowhead stocks has been high due to the need to set appropriate quotas for aboriginal hunts. Additional subdivision has been proposed based on historical whaling records, traditional knowledge, and geographically dispersed feeding grounds (Rugh et al. 2003). Especially within the BCB stock, where aboriginal whaling continues and the population is rebounding, extensive studies have been conducted to try to determine whether multiple isolated populations could have existed and potentially still exist, using a variety of methods including genetics (mitochondrial sequences and nuclear microsatellites; Jorde et al. 2007, LeDuc et al. 2008, Givens et al. 2010), population modeling (Archer et al. 2010), and traditional knowledge (Noongwook et al. 2007). Prior to this study, microsatellite genotype data have been used twice to assess population structure in BCB bowheads (Jorde et al. 2007, Givens et al. 2010). These 2 studies used mostly non-overlapping sets of microsatellites due to difficulty in scoring and reproducibility of some of the loci from the Jorde et al. (2007) study and a previous study by Rooney et al. (1999), as explained by Givens et al. (2010). This is a critical limitation of microsatellite markers, especially if long time periods lapse between additions of samples to monitor populations (e.g. Davison \& Chiba 2003, Morin et al. $2009 b)$. As it is likely that another decade will elapse before the next major study is completed on bowhead whale population structure, there is good reason to develop a nuclear genetic marker that provides consistent genotypes over time and technologies and has sufficient power to address demographic and population structure questions.

\section{MATERIALS AND METHODS}

\section{Samples}

Skin samples were obtained from stranded dead animals, projectile-dart biopsy of live animals in the field, and whales taken in the annual subsistence hunts. A complete list of BCB and SO samples and stratification information are presented in Table S1 in the Supplement at www.int-res.com/articles/suppl/ n019p129_supp.xls. Samples were stored frozen in $20 \%$ (v/v) dimethyl sulfoxide (DMSO) solution saturated with $\mathrm{NaCl}$ until ready for DNA extraction (Gemmell \& Akiyama 1996, Amos 1997). DNA was extracted from soft tissues using a variety of methods: lithium chloride (Gemmell \& Akiyama 1996), sodium chloride protein precipitation (modified from Miller et al. 1988), silica-based filter purification (Qiagen), and standard phenol/chloroform extraction. DNA was extracted from historical bone and baleen samples as described in Morin et al. (2006).

Samples were stratified by temporal, spatial, and age-related criteria for analysis. The spatial and temporal strata included samples from multiple years (Table S1). As in LeDuc et al. (2008), spatial strata included Barrow (the village on Alaska's North Slope with the largest hunt), the entire North Slope of Alaska (NS), St. Lawrence Island (SLI), Gambell and Savoonga (2 villages on SLI), Alaska (NS plus SLI), and Chukotka, Russia. These strata were justified based on hypotheses of spatially separated populations that may be differentially harvested near different villages in Alaska and Russia, and on hypotheses of different migration timing of populations harvested along the North Slope of Alaska (for details, see LeDuc et al. 2008). In addition, this study included strata for geographically separated populations in SO and EC (including samples from Hudson Bay and the Davis Straits). This study had a larger BCB population sample size (for SNP data only) than previous studies (Rooney et al. 2001, LeDuc et al. 2005, 2008, Givens et al. 2010), but the sample set included the same samples as were used for microsatellite analysis (Givens et al. 2010) and mtDNA analysis. Additional samples for SNP analysis were collected from aboriginal hunt and live-animal biopsies in 2 more recent years since the previous data were generated, as well as from historical Barrow and SLI bone and baleen samples from the 1960s and early 1970s. Mostly non-overlapping sets of samples from EC were used for SNPs (present study) and microsatellites (Givens et al. 2010), but samples were from the same geographic and genetic stock. The 
microsatellite analyses did not include any of the historical samples; these samples were used only in mtDNA (SLI samples) and SNP analyses (all samples). Seasonal temporal strata within Barrow and the NS included spring (Apr-Jun) and fall (Aug-Oct) hunting seasons, and in SLI they included spring (Apr-May) and fall (Nov-Jan). For age group temporal comparisons, samples were divided into birthyear strata, based on the year of catch and age estimates from amino acid racemization of lens proteins and baleen growth increments (George et al. 1999, Lubetkin \& Zeh 2006, LeDuc et al. 2008, Lubetkin et al. 2008). Four strata were constructed to include animals born prior to the low point in the population's history (prior to 1918) and in approximately 30-yr increments after and including 1918 (i.e. 1918-1949, 1950-1979, and after 1979), plus combinations of the 2 earliest strata to increase sample size, as in LeDuc et al. (2008).

\section{Genetic data}

Bowhead SNPs were ascertained from a rangewide set of samples and assays previously described (Morin et al. 2010). SNP genotypes were generated as described in Morin \& McCarthy (2007). Data from 22 microsatellite loci were from Givens et al. (2010), and mtDNA data were described in LeDuc et al. (2008).

Genetic data quality analyses and error rates for the bowhead SNP and microsatellite genotypes and mtDNA sequences have been reported previously (LeDuc et al. 2008, Morin et al. 2009a, Givens et al. 2010). For the remainder of the modern and historical samples added in this study, we determined error rates based on duplicate genotyping of random samples throughout the genotyping process, re-genotyping of 42 samples across all 42 SNP loci after the other genotypes had been generated, and replication of 7 control samples in every SNP assay on each 96well plate of samples. Historical samples were prescreened for DNA quantity (Morin et al. 2001, 2007, Morin \& McCarthy 2007), and SNP genotypes for these samples were replicated at least 5 times. Genotypes were confirmed by the presence of both alleles at least twice for heterozygotes, or at least 3 replications of homozygous genotypes. Twenty-two historical and modern samples that frequently resulted in 3 or fewer called genotypes among replicates, or $<30$ completed genotypes, were excluded from all further analyses.

Complete SNP genotype sets for all samples were screened for heterozygote deficiency using the exact test in GenePop (Rousset 2008), and significant deviation from Hardy-Weinberg equilibrium (HWE) expectations was determined after Bonferroni correction for multiple tests for each marker type and in each population.

The effect of individual sample genotypes on deviations from HWE (which could indicate poor sample quality, possibly resulting in allelic dropout) was examined through jackknife analysis (Morin et al. 2009a). Presence of unknown duplicate samples was detected using the program 'DropOut' (McKelvey \& Schwartz 2004), which identifies perfect and nearperfect composite genotype matches.

All SNP loci were analyzed for linkage disequilibrium using default settings in the program GenePop v.4.0.1 (Rousset 2008). SNPs known to be linked (found in the same DNA sequence) were combined into haplotypes (sets of alleles shared on each chromosome for 2 or more SNPs that are close together) using the program PHASE (Stephens et al. 2001), using one million replicates and a haplotype probability cutoff of 0.5 for inferred haplotypes to reduce bias caused by preferential exclusion of double heterozygote samples. PHASE infers haplotypes even in the absence of genotype data, which can cause a bias in haplotype frequencies among populations. We performed replicate analyses of summary statistics using the default PHASE function and by removing genotypes inferred when one or more of the linked genotypes were missing (see Mesnick et al. 2011).

SNPs were checked for evidence of divergent selection among populations using the program BayeScan (Foll \& Gaggiotti 2008) based on allele frequency differences among the 3 stocks, using default Markov chain Monte Carlo parameters in the program.

\section{Analytical methods}

We calculated several divergence metrics for each data set. $F_{\mathrm{ST}}, G^{\prime \prime}{ }_{\mathrm{ST}}$ (Meirmans \& Hedrick 2011) and $\chi^{2}$ were calculated using custom scripts coded in R (R Development Core Team 2011) by F. I. Archer. For all analyses, 1000 permutations were used to calculate the p-value. $F_{\mathrm{ST}}$ and $G^{\prime \prime}{ }_{\mathrm{ST}}$ are both measures of divergence (see 'Results' for more details), and $\chi^{2}$ is a statistical test of significance applied to allele frequency differences between populations.

Estimation of the effective population size was conducted using the program LDNe (Waples \& Do 2008). Default minimum allele frequency cutoffs were used under a random mating model. 
We used random re-sampling (without replacement) of subsets of loci (5 or 10 loci) to estimate power of different numbers of SNPs and microsatellites to detect the bowhead stocks. Data were sampled 100 times for genetic analysis for both 5- and 10-loci subsets. Power to detect population structure was quantified as the percentage of analyses of each subset with permutation $p$-values $<0.05$. To examine the effect of sample size on the power to detect stock structure, we also analyzed 1000 replicates of randomly selected subsamples of 20 and 40 individuals per population. For pairwise tests of each subsample, 500 permutations were conducted in order to estimate p-values.

We used the program STRUCTURE 2.3.1 (Pritchard et al. 2000, Falush et al. 2003, Hubisz et al. 2009) to infer the number of populations and assign samples to putative populations. We used the same parameters Givens et al. (2010) used for bowhead whale microsatellite analysis: an admixture model with correlated allele frequencies and a burn-in of 50000 iterations followed by a run of 1000000 iterations. We first ran all analyses without using location information as a prior, as was done by Givens et al. (2010), and then repeated all analyses with location as a prior. For the latter analyses, the sampling location of each sample was defined as the population (BCB, EC, or SO) from which it was sampled. We investigated models containing $k=1$ to 5 groups and ran STRUCTURE 10 times for each $k$. We evaluated support for different values of $k$ by calculating both the average log probability of the data (ln $\mathrm{P}(\mathrm{D})$ ) and the metric $\Delta k$ (Evanno et al. 2005) for each model. To quantify how well individuals were assigned to populations, we first calculated the mean assignment probabilities for all individuals from each population within a run, and then averaged the mean assignment probability for each population across runs for a given value of $k$.

We investigated the performance of STRUCTURE as a function of the number of markers used by randomly choosing subsets of the microsatellite markers to include in the analysis. For a given number of markers, we generated 10 data sets, each containing a different randomly chosen subset of markers. We used this approach to generate data sets containing 5, 10, and 15 microsatellite markers. We did not perform this analysis on the SNP data because power was already so low with the complete set that further reduction in the number of markers would be uninformative.

Individual assignment to 2 of the putative source populations (BCB and SO) was investigated using GeneClass2 (version 2.0) (Piry et al. 2004). The EC population was not included because the SNP and microsatellite samples were not overlapping. We used the combined nuclear data set comprised of microsatellites and SNPs, as well as each set separately, and the Bayesian assignment criterion of Rannala \& Mountain (1997) to calculate the assignment likelihoods for samples from the BCB $(\mathrm{N}=281)$ and SO $(\mathrm{N}=49)$ populations. For all analyses, we set the default frequency for missing alleles at 0.01 , and the assignment threshold at the default value of 0.05 .

\section{RESULTS}

\section{Samples and genotypes}

The final SNP sample set consisted of 526 samples after removal of poor quality and duplicated samples (see below). Population samples were: BCB $=427$ (including 49 historical bone and baleen samples), $\mathrm{EC}=49$, and $\mathrm{SO}=50$ (Fig. 1).

Summary statistics for the SNP loci are given in Table 1. Replicate analysis of the bowhead SNP data indicated a per-allele error rate of $0.07-0.2 \%$ in mod-

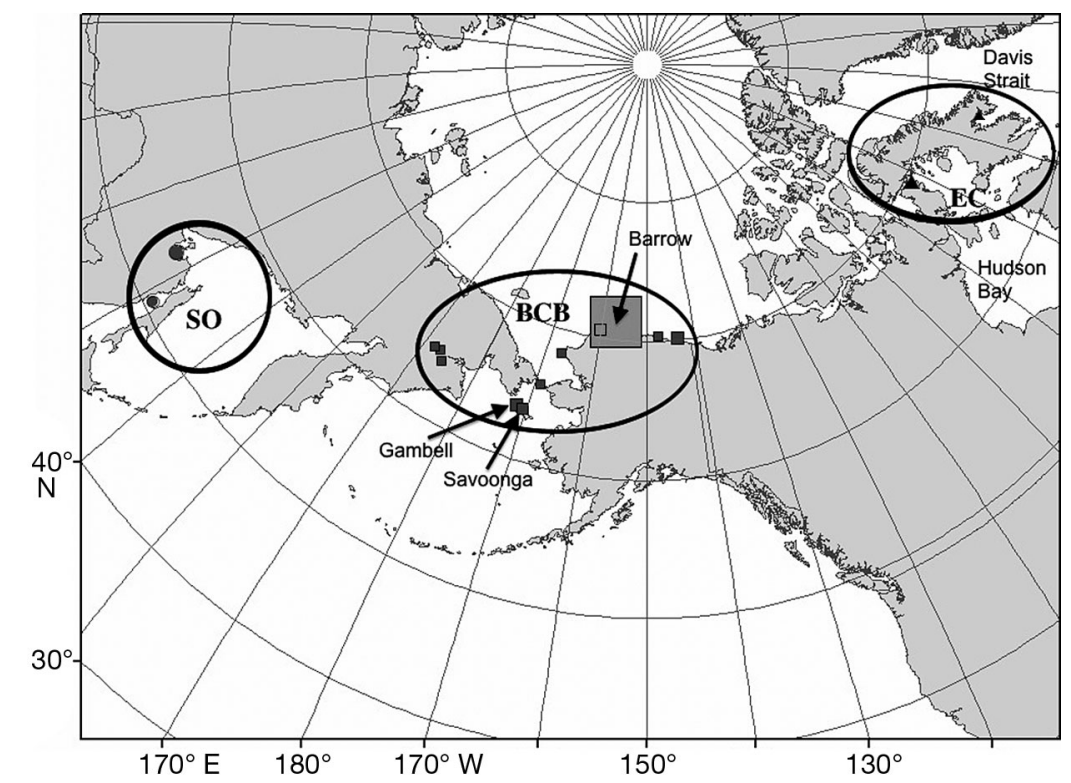

Fig. 1. Sampling locations and populations (Bering/Chukchi/Beaufort Seas, BCB: squares; Sea of Okhotsk, SO: circles; Eastern Canada, EC: triangles) for samples used in this study. The size of the symbol is proportional to the number of samples from that location. Samples from far-eastern Russia that appear to be on land are from the Senyavin Strait 
Table 1. Descriptive statistics of microsatellite and phased single nucleotide polymorphism (SNP) loci in the 3 bowhead whale populations, showing allelic richness, expected $\left(H_{\mathrm{e}}\right)$ and observed $\left(H_{\mathrm{o}}\right)$ heterozygosity, genetic diversity $(\theta)$ and p-values for deviations from Hardy-Weinberg equilibrium [HWE(p)]. Significance of HWE(p) after Bonferroni correction for multiple tests is indicated in bold. SNP locus names are for phased SNPs when multiple SNPs were used from a single sequenced locus, and include the IUPAC SNP letters and positions as described in Morin et al. (2010). BCB: Bering/Chukchi/Beaufort Seas; EC: Eastern Canada; SO: Sea of Okhotsk. N: number of genotyped whales

\begin{tabular}{|c|c|c|c|c|c|c|}
\hline \multirow[t]{2}{*}{ Locus } & \multirow{2}{*}{ No. of alleles } & \multirow{2}{*}{ Allelic richness } & \multirow{2}{*}{$\begin{array}{c}(\mathrm{N}= \\
H_{\mathrm{e}}\end{array}$} & \multirow{2}{*}{\multicolumn{2}{|c|}{ 02)- }} & \multirow[b]{2}{*}{ HWE (p) } \\
\hline & & & & & & \\
\hline \multicolumn{7}{|l|}{ Microsatellites } \\
\hline Bmy1 & 10 & 0.033 & 0.81 & 0.82 & 0.61 & 0.55 \\
\hline Bmy $^{2}{ }^{a}$ & 11 & 0.037 & 0.77 & 0.75 & 0.57 & 0.18 \\
\hline Bmy 7 & 13 & 0.042 & 0.79 & 0.81 & 0.59 & 0.17 \\
\hline Bmy8 & 16 & 0.053 & 0.80 & 0.79 & 0.59 & 0.51 \\
\hline Bmy10 & 22 & 0.072 & 0.93 & 0.90 & 0.69 & 0.06 \\
\hline Bmy11 & 14 & 0.046 & 0.88 & 0.87 & 0.65 & 0.47 \\
\hline Bmy12 & 27 & 0.088 & 0.92 & 0.93 & 0.69 & 0.36 \\
\hline Bmy14 & 6 & 0.020 & 0.56 & 0.52 & 0.41 & 0.02 \\
\hline Bmy16 & 8 & 0.026 & 0.77 & 0.79 & 0.57 & 0.91 \\
\hline Bmy18 & 17 & 0.056 & 0.90 & 0.88 & 0.67 & 0.10 \\
\hline Bmy19 & 16 & 0.053 & 0.87 & 0.86 & 0.65 & 0.12 \\
\hline Bmy26 & 22 & 0.073 & 0.93 & 0.91 & 0.69 & 0.07 \\
\hline Bmy33 & 12 & 0.039 & 0.81 & 0.80 & 0.60 & 0.60 \\
\hline Bmy36 & 28 & 0.092 & 0.94 & 0.94 & 0.70 & 0.69 \\
\hline Bmy41 & 22 & 0.072 & 0.91 & 0.90 & 0.68 & 0.09 \\
\hline Bmy42 & 11 & 0.036 & 0.79 & 0.74 & 0.59 & 0.07 \\
\hline Bmy49 & 24 & 0.078 & 0.90 & 0.91 & 0.67 & 0.39 \\
\hline Bmy53 & 17 & 0.056 & 0.88 & 0.88 & 0.65 & 0.39 \\
\hline Bmy54 & 8 & 0.026 & 0.71 & 0.70 & 0.53 & 0.05 \\
\hline Bmy55 & 6 & 0.020 & 0.71 & 0.69 & 0.53 & 0.06 \\
\hline Bmy57 & 9 & 0.030 & 0.61 & 0.59 & 0.45 & 0.00 \\
\hline Bmy58 & 27 & 0.089 & 0.93 & 0.93 & 0.69 & 0.54 \\
\hline Average & 15.73 & 0.05 & 0.82 & 0.81 & 0.61 & \\
\hline \multicolumn{7}{|l|}{ SNPs } \\
\hline BmC5R700_Y910 & 3 & 0.007 & 0.36 & 0.37 & 0.27 & 0.73 \\
\hline BmCATR205_R212 & 4 & 0.009 & 0.37 & 0.37 & 0.28 & 0.67 \\
\hline BmCHYY286_R417 & 4 & 0.009 & 0.62 & 0.63 & 0.46 & 0.54 \\
\hline BmCOL3A1Y82 & 2 & 0.006 & 0.35 & 0.30 & 0.26 & 0.01 \\
\hline BmCSF2S320 & 2 & 0.005 & 0.50 & 0.53 & 0.37 & 0.94 \\
\hline BmEDN1Y91 & 2 & 0.005 & 0.38 & 0.41 & 0.29 & 0.94 \\
\hline BmFESY136 & 2 & 0.005 & 0.36 & 0.37 & 0.27 & 0.74 \\
\hline BmMPOR184_R284 & 3 & 0.007 & 0.61 & 0.57 & 0.46 & 0.05 \\
\hline BmPMKS494 & 2 & 0.005 & 0.45 & 0.42 & 0.34 & 0.13 \\
\hline Bmys108D91 & 2 & 0.005 & 0.29 & 0.29 & 0.22 & 0.55 \\
\hline Bmys1R248 & 2 & 0.005 & 0.01 & 0.01 & 0.01 & 1.00 \\
\hline Bmys28Y154_R162 & 4 & 0.009 & 0.56 & 0.55 & 0.42 & 0.58 \\
\hline Bmys31Y94 & 2 & 0.006 & 0.25 & 0.27 & 0.19 & 0.97 \\
\hline Bmys34M251 & 2 & 0.005 & 0.10 & 0.10 & 0.07 & 0.65 \\
\hline Bmys368R272 & 2 & 0.005 & 0.28 & 0.30 & 0.21 & 0.91 \\
\hline Bmys382Y279 & 2 & 0.005 & 0.18 & 0.17 & 0.14 & 0.06 \\
\hline Bmys387R245_R361 & 3 & 0.007 & 0.34 & 0.35 & 0.25 & 0.28 \\
\hline Bmys395Y158 & 2 & 0.005 & 0.50 & 0.50 & 0.37 & 0.49 \\
\hline Bmys402M56 & 2 & 0.005 & 0.48 & 0.24 & 0.35 & 0.00 \\
\hline Bmys404Y286_K316 & 4 & 0.010 & 0.63 & 0.63 & 0.47 & 0.49 \\
\hline Bmys410K107 & 2 & 0.005 & 0.49 & 0.49 & 0.36 & 0.53 \\
\hline Bmys412R79_R463 & 3 & 0.007 & 0.43 & 0.52 & 0.32 & 1.00 \\
\hline Bmys414R127 & 2 & 0.005 & 0.46 & 0.46 & 0.34 & 0.50 \\
\hline Bmys42aK46_aR225_bK232 & 7 & 0.018 & 0.79 & 0.80 & 0.59 & 0.01 \\
\hline Bmys43Y237_Y377 & 4 & 0.010 & 0.60 & 0.60 & 0.45 & 0.47 \\
\hline Bmys48S269 & 2 & 0.005 & 0.49 & 0.51 & 0.36 & 0.89 \\
\hline Bmys60Y148_R260 & 4 & 0.009 & 0.20 & 0.20 & 0.15 & 0.29 \\
\hline Bmys92Y230_K271 & 3 & 0.007 & 0.59 & 0.61 & 0.44 & 0.89 \\
\hline Bmys96R421 & 2 & 0.005 & 0.35 & 0.39 & 0.26 & 0.99 \\
\hline Average & 2.76 & 0.01 & 0.41 & 0.41 & 0.31 & \\
\hline
\end{tabular}


Table 1 (continued)

\begin{tabular}{|c|c|c|c|c|c|c|c|c|c|c|c|}
\hline \multicolumn{6}{|c|}{$\mathrm{SO}(\mathrm{N}=60)$} & \multicolumn{6}{|c|}{$-\mathrm{EC}(\mathrm{N}=47)$} \\
\hline No. of alleles & Allelic richness & $H_{\mathrm{e}}$ & $H_{\mathrm{o}}$ & $\theta$ & $\overline{\operatorname{HWE}(p)}$ & No. of alleles & Allelic richness & $H_{\mathrm{e}}$ & $H_{\mathrm{o}}$ & $\theta$ & $\operatorname{HWE}(p)$ \\
\hline 8 & 0.133 & 0.82 & 0.77 & 0.61 & 0.42 & 9 & 0.191 & 0.82 & 0.83 & 0.61 & 0.72 \\
\hline 8 & 0.133 & 0.77 & 0.70 & 0.57 & 0.13 & & & & & & \\
\hline 10 & 0.167 & 0.87 & 0.95 & 0.65 & 0.98 & 8 & 0.170 & 0.78 & 0.70 & 0.58 & 0.26 \\
\hline 9 & 0.150 & 0.81 & 0.85 & 0.60 & 0.90 & 10 & 0.217 & 0.83 & 0.80 & 0.62 & 0.43 \\
\hline 15 & 0.250 & 0.89 & 0.93 & 0.66 & 0.80 & 18 & 0.383 & 0.92 & 0.98 & 0.68 & 0.95 \\
\hline 9 & 0.150 & 0.79 & 0.73 & 0.59 & 0.36 & 11 & 0.239 & 0.88 & 0.91 & 0.66 & 0.71 \\
\hline 11 & 0.183 & 0.84 & 0.87 & 0.63 & 0.43 & 16 & 0.364 & 0.90 & 0.98 & 0.67 & 0.97 \\
\hline 3 & 0.050 & 0.48 & 0.42 & 0.35 & 0.21 & 6 & 0.128 & 0.58 & 0.57 & 0.44 & 0.52 \\
\hline 6 & 0.102 & 0.76 & 0.80 & 0.57 & 0.86 & 7 & 0.149 & 0.76 & 0.74 & 0.57 & 0.00 \\
\hline 9 & 0.150 & 0.76 & 0.77 & 0.57 & 0.52 & 14 & 0.298 & 0.89 & 0.96 & 0.66 & 0.91 \\
\hline 12 & 0.200 & 0.83 & 0.80 & 0.62 & 0.00 & 10 & 0.213 & 0.87 & 0.89 & 0.65 & 0.73 \\
\hline 16 & 0.281 & 0.89 & 0.88 & 0.67 & 0.02 & 18 & 0.383 & 0.91 & 0.98 & 0.68 & 1.00 \\
\hline 8 & 0.133 & 0.80 & 0.72 & 0.60 & 0.19 & 8 & 0.170 & 0.78 & 0.83 & 0.58 & 0.66 \\
\hline 21 & 0.350 & 0.89 & 0.88 & 0.66 & 0.60 & 19 & 0.413 & 0.94 & 0.96 & 0.70 & 0.67 \\
\hline 11 & 0.186 & 0.83 & 0.85 & 0.62 & 0.64 & 19 & 0.404 & 0.91 & 0.87 & 0.68 & 0.42 \\
\hline 7 & 0.117 & 0.82 & 0.85 & 0.61 & 0.83 & 11 & 0.234 & 0.85 & 0.79 & 0.63 & 0.19 \\
\hline 14 & 0.233 & 0.89 & 0.92 & 0.66 & 0.76 & 19 & 0.404 & 0.88 & 0.83 & 0.65 & 0.30 \\
\hline 10 & 0.167 & 0.79 & 0.75 & 0.59 & 0.24 & 16 & 0.340 & 0.90 & 0.89 & 0.67 & 0.44 \\
\hline 6 & 0.100 & 0.76 & 0.77 & 0.56 & 0.69 & 7 & 0.149 & 0.77 & 0.77 & 0.57 & 0.22 \\
\hline 6 & 0.100 & 0.53 & 0.53 & 0.40 & 0.69 & 6 & 0.128 & 0.72 & 0.66 & 0.54 & 0.23 \\
\hline 5 & 0.083 & 0.56 & 0.55 & 0.42 & 0.41 & 8 & 0.170 & 0.65 & 0.64 & 0.49 & 0.61 \\
\hline 14 & 0.255 & 0.90 & 0.95 & 0.67 & 0.59 & 21 & 0.447 & 0.93 & 0.89 & 0.69 & 0.49 \\
\hline 9.91 & 0.17 & 0.79 & 0.78 & 0.59 & & 12.43 & 0.27 & 0.83 & 0.83 & 0.62 & \\
\hline \multicolumn{6}{|c|}{$-\mathrm{SO}(\mathrm{N}=50)$} & & $-\mathrm{EC}$ & $(\mathrm{N}=$ & 9) & & \\
\hline 3 & 0.060 & 0.37 & 0.36 & 0.28 & 0.33 & 3 & 0.063 & 0.48 & 0.52 & 0.36 & 0.79 \\
\hline 3 & 0.060 & 0.60 & 0.72 & 0.45 & 0.98 & 4 & 0.082 & 0.35 & 0.37 & 0.26 & 0.52 \\
\hline 3 & 0.060 & 0.47 & 0.50 & 0.35 & 0.40 & 3 & 0.061 & 0.56 & 0.55 & 0.42 & 0.44 \\
\hline 2 & 0.048 & 0.31 & 0.29 & 0.23 & 0.45 & 2 & 0.041 & 0.39 & 0.49 & 0.29 & 0.99 \\
\hline 2 & 0.040 & 0.47 & 0.56 & 0.35 & 0.96 & 2 & 0.041 & 0.50 & 0.61 & 0.37 & 0.97 \\
\hline 2 & 0.040 & 0.34 & 0.42 & 0.25 & 1.00 & 2 & 0.041 & 0.43 & 0.45 & 0.32 & 0.74 \\
\hline 2 & 0.040 & 0.23 & 0.26 & 0.17 & 1.00 & 2 & 0.041 & 0.38 & 0.39 & 0.29 & 0.66 \\
\hline 3 & 0.063 & 0.59 & 0.69 & 0.44 & 0.82 & 4 & 0.085 & 0.64 & 0.60 & 0.47 & 0.31 \\
\hline 2 & 0.041 & 0.37 & 0.37 & 0.28 & 0.59 & 2 & 0.041 & 0.40 & 0.43 & 0.30 & 0.79 \\
\hline 2 & 0.040 & 0.50 & 0.46 & 0.37 & 0.39 & 2 & 0.043 & 0.30 & 0.32 & 0.22 & 0.83 \\
\hline 2 & 0.040 & 0.26 & 0.22 & 0.19 & 0.28 & 1 & 0.020 & 0.00 & 0.00 & 0.00 & NA \\
\hline 3 & 0.060 & 0.50 & 0.54 & 0.37 & 0.39 & 3 & 0.061 & 0.59 & 0.49 & 0.44 & 0.07 \\
\hline 2 & 0.040 & 0.23 & 0.14 & 0.17 & 0.02 & 2 & 0.041 & 0.22 & 0.20 & 0.16 & 0.53 \\
\hline 2 & 0.040 & 0.24 & 0.28 & 0.18 & 1.00 & 2 & 0.043 & 0.04 & 0.04 & 0.03 & 1.00 \\
\hline 2 & 0.040 & 0.30 & 0.36 & 0.22 & 1.00 & 2 & 0.041 & 0.39 & 0.49 & 0.29 & 0.99 \\
\hline 2 & 0.040 & 0.10 & 0.10 & 0.07 & 1.00 & 2 & 0.041 & 0.12 & 0.08 & 0.09 & 0.15 \\
\hline 3 & 0.060 & 0.46 & 0.40 & 0.34 & 0.17 & 3 & 0.061 & 0.44 & 0.39 & 0.33 & 0.07 \\
\hline 2 & 0.040 & 0.50 & 0.50 & 0.37 & 0.61 & 2 & 0.042 & 0.50 & 0.54 & 0.38 & 0.79 \\
\hline 2 & 0.040 & 0.50 & 0.20 & 0.37 & 0.00 & 2 & 0.041 & 0.50 & 0.16 & 0.37 & 0.00 \\
\hline 3 & 0.061 & 0.66 & 0.69 & 0.49 & 0.77 & 3 & 0.061 & 0.64 & 0.67 & 0.48 & 0.61 \\
\hline 2 & 0.040 & 0.29 & 0.30 & 0.21 & 0.81 & 2 & 0.043 & 0.50 & 0.48 & 0.37 & 0.52 \\
\hline 4 & 0.080 & 0.42 & 0.44 & 0.31 & 0.70 & 3 & 0.061 & 0.38 & 0.41 & 0.28 & 0.15 \\
\hline 2 & 0.041 & 0.29 & 0.27 & 0.22 & 0.43 & 2 & 0.041 & 0.48 & 0.45 & 0.36 & 0.44 \\
\hline 7 & 0.156 & 0.81 & 0.78 & 0.60 & 0.15 & 7 & 0.146 & 0.81 & 0.85 & 0.60 & 0.87 \\
\hline 3 & 0.063 & 0.53 & 0.60 & 0.40 & 0.91 & 4 & 0.082 & 0.58 & 0.65 & 0.43 & 0.87 \\
\hline 2 & 0.043 & 0.50 & 0.40 & 0.37 & 0.15 & 2 & 0.041 & 0.50 & 0.37 & 0.37 & 0.05 \\
\hline 4 & 0.080 & 0.41 & 0.34 & 0.31 & 0.06 & 4 & 0.082 & 0.33 & 0.27 & 0.25 & 0.01 \\
\hline 4 & 0.083 & 0.51 & 0.65 & 0.38 & 0.99 & 3 & 0.061 & 0.44 & 0.49 & 0.33 & 0.72 \\
\hline 2 & 0.040 & 0.43 & 0.46 & 0.32 & 0.78 & 2 & 0.041 & 0.17 & 0.18 & 0.13 & 1.00 \\
\hline 2.66 & 0.05 & 0.42 & 0.42 & 0.31 & & 2.66 & 0.05 & 0.42 & 0.41 & 0.31 & \\
\hline
\end{tabular}


ern samples (depending on which group of replicates was analyzed; see 'Materials and methods'), and $1.1 \%$ in historical samples (Morin \& McCarthy 2007). We removed 22 samples prior to analysis due to low genotyping success rate ( $<30$ completed genotypes). Thirteen samples were determined to be duplicates of others in the sample set (either repeat sampling of the same individual or matching of a skull sample to a tissue sample from a harvested animal). In the remaining samples, all samples differed by 5 to 15 SNP genotypes out of 42 .

Among the 25 loci known from sequencing to be physically linked in 12 locus groups, linkage analysis indicated only 3 cases of significant $(\mathrm{p}<$ 0.05 ) linkage disequilibrium across all 3 populations and 3 cases across 2 populations (data not shown). No other SNP locus pairs showed significant linkage across all 3 populations, though 5 locus pairs were significant across 2 populations. Given that the linkage was not strong enough to show up across all 3 population samples, we only inferred phased haplotypes from loci known to be physically linked from our SNP discovery sequencing (Morin et al. 2010). Analysis of the phased haplotypes for potential bias due to inference of haplotypes from missing data indicated that $1.6 \%(103 / 6324)$ were inferred by PHASE when one or more of the genotypes was missing. No loci changed from significant to non-significant deviation from HWE expectations (or vice versa) when haplotypes were inferred from missing data or removed. We also calculated $F_{\mathrm{ST}}$ and $\chi^{2}$ statistics for the 3 stock pairwise comparisons. All p-values were consistent $(>0.05$ or $<0.05)$ between SNP data sets (with and without inference from missing data), and $F_{\mathrm{ST}}$ values varied by $<0.0003$. Based on these results, all further analyses were performed on the phased SNP data with haplotypes inferred from missing genotypes (default method). The resulting set of 29 single- and phasedloci are hereafter referred to as the 'phased SNP loci' (locus summary statistics are in Table 1 and allele frequencies are in Table 2).

Analysis of deviations from HWE in each population showed that only one SNP locus deviated signif- icantly from HWE in all 3 geographic populations (Table 1). That locus (Bmys402) was previously known to be X-linked and therefore was expected to deviate from HWE expectations. No other loci deviated significantly from HWE expectations in any of the populations ( $\mathrm{p}$-value cutoff corrected for multiple tests).

The program BayeScan uses allele frequency differences among populations to infer evidence of diversifying selection. Values between 0 and 0.5 are considered to indicate no evidence of selection, and values of $0.5-1.0$ 'substantial', 1.0-1.5 'strong', 1.5-2 'very strong' and $>2$ 'decisive' evidence of diversifying selection (Foll \& Gaggiotti 2008). Analysis of the SNP data (42 individual loci) among the 3 stocks indicated that 2 loci (Bmys1R248 and Bmys34M251) exhibited 'substantial' evidence of positive selection, with $\log _{10}$ Bayes factors (BF) slightly above 0.5. All other loci were below the $\log _{10} \mathrm{BF}$ threshold value of 0.5. All loci were included in subsequent analyses. 


\section{Geographic and temporal genetic structure}

Bowhead whale population structure was previously examined extensively using mitochondrial DNA (LeDuc et al. 2008) and microsatellites (Givens et al. 2010). For the present study, we compared results based on the within-BCB strata presented in LeDuc et al. (2008) plus inter-stock pairwise comparisons, and re-analyzed the microsatellite data using the same methods and as many overlapping samples as possible between microsatellites and SNPs. We performed standard population differentiation analyses and tests for significance on the phased SNP loci data set and found that $F_{\mathrm{ST}}$ and $\chi^{2}$ results remained consistent for all spatial comparisons, with significant $F_{\text {ST }}$ ranging from approximately 0.005 to 0.04 among the 3 geographically separated populations with both microsatellites and SNPs (Table 3). Combining SNPs and microsatellites, which would be expected to increase statistical power over either single data set, did not result in detection of additional population structure within the BCB population (Table 3).

It has been argued that it is not appropriate to compare $F_{\mathrm{ST}}$ values between groups of markers with different levels of heterozygosity (Hedrick 2005, but see Hubisz et al. 2009), so we computed Meirmans \& Hedrick's (2011) unbiased $G^{\prime \prime}{ }_{\text {ST }}$ to account for different levels of heterozygosity. $F_{\mathrm{ST}}$ values were very similar between SNPs and microsatellites, but $G^{\prime \prime}$ ST was lower than $F_{\mathrm{ST}}$ for $\mathrm{BCB}$ versus $\mathrm{EC}$ and higher for $\mathrm{SO}$ versus EC and BCB (Table 3). $G^{\prime \prime}{ }_{\mathrm{ST}}$ is supposed to be relatively unaffected by heterozygosity and therefore can be used more appropriately to compare results from markers with different numbers of alleles such as microsatellites and SNPs. For our population comparisons with both SNPs and microsatellites, levels of differentiation are expected to be small due to historical connectivity. We would expect $G^{\prime \prime}$ sT and $F_{\mathrm{ST}}$ to be similar if heterozygosity was the only difference. In contrast, estimates of $G^{\prime \prime}{ }_{\text {ST }}$ differ by up to 3fold between marker sets for the same strata comparisons. Two evaluations of published data have also shown that there remains a positive relationship between intra-population heterozygosity and $G_{\text {ST }}^{\prime}$ (a close analog of $G^{\prime \prime}{ }_{\text {ST }}$ ) (Heller \& Siegismund 2009, Meirmans \& Hedrick 2011), and multiple possible explanations for these differences have been discussed (Balloux \& Lugon-Moulin 2002, Jost 2009, Ryman \& Leimar 2009, Meirmans \& Hedrick 2011). Based on the recommendations of Meirmans \& Hedrick (2011), we believe that $F_{\mathrm{ST}}$ remains a good measure of differentiation for SNPs, while $G^{\prime \prime}$ ST may better reflect historical demographic patterns inferred from microsatellites, though precision should be estimated using a bootstrap method due to potentially high variance among loci.

Although there are limitations to using $F_{\mathrm{ST}}$ to estimate the amount of gene flow, we do so here in order to get a rough idea of the level of gene flow that is consistent with our $F_{\mathrm{ST}}$ estimates. If we use Wright's (1931) formula $F_{\mathrm{ST}}=1 /\left(4 N_{\mathrm{e}} m+1\right)$, and assuming that the $N_{\mathrm{e}}$ of each is either 400 (estimated from genetic data; see below) or 9100 (breeding adults, $65 \%$ of current population; Taylor et al. 2007), generation time $=52.3$ (Taylor et al. 2007), and using the average $F_{\mathrm{ST}}$ for microsatellites and SNPs of 0.0065 (Table 3), we get $N_{\mathrm{e}} m=$ $38.2, m=0.1-0.004$, and annual dispersal rate $=0.002-$ $8 \times 10^{-5}$ between $\mathrm{BCB}$ and $\mathrm{EC}$, or 0.7 individuals per year. Thus, although genetic differentiation as measured by $F_{\mathrm{ST}}$ is low, the populations remain demographically independent $(<1$ individual per year between populations with $>9000$ breeding adults) (Taylor 1997).

Age structure comparisons between the older (born before 1950) and younger (born after 1979) animals within the BCB stock were statistically significant $\left(\chi^{2}\right.$ analysis; Table 3$)$ with mitochondrial DNA, microsatellites and combined microsatellite and SNP genotypes, but not for SNPs alone. In general, these results support the 'generational gene shift' hypothesis that suggested that 'the historical population dynamics of the BCB bowhead whales-extreme reduction followed by rapid recovery - have led to changes in haplotype frequencies across generations, at least between those generations on either side of the population's nadir' (LeDuc et al. 2008).

\section{Demographic analyses}

Estimates of $N_{\mathrm{e}}$ varied significantly between data sets, with SNPs providing higher estimates and wider 95\% confidence intervals (CIs) than microsatellites (Table 4). The combination of SNPs and microsatellites provided estimates of $N_{\mathrm{e}}$ (405 and 137 in BCB and $\mathrm{SO}$, respectively) similar to microsatellites alone $(357,112)$, with a narrower $95 \%$ CI for $\mathrm{BCB}$ and approximately equivalent $95 \%$ CIs for SO (Table 4 ).

\section{Statistical power and assignment}

Given the relatively large and uneven sample sizes among populations, we randomly sub-sampled the 3 population samples and conducted standard tests of differentiation. Results indicate that power remained 


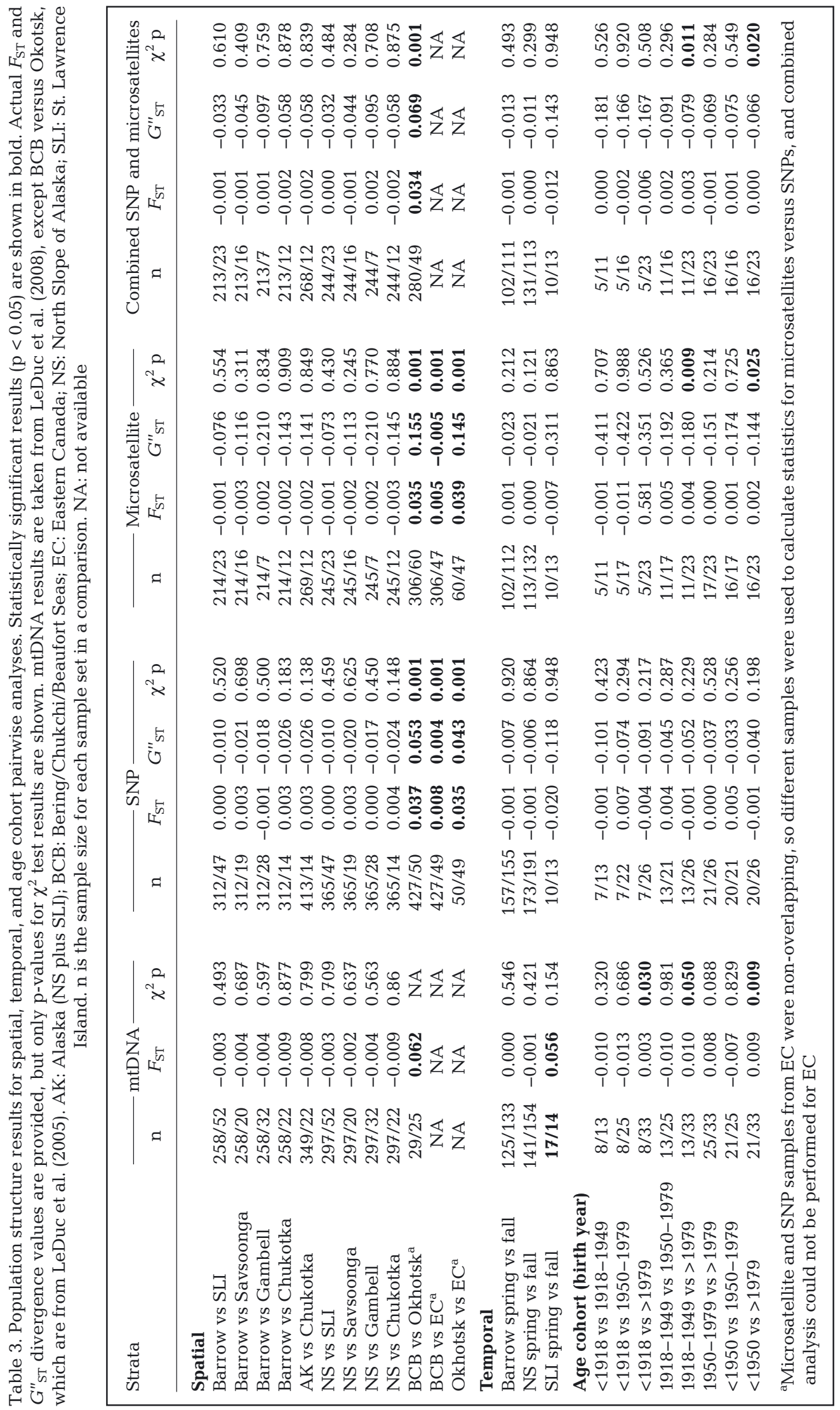


Table 4. Estimates of effective population size $\left(N_{\mathrm{e}}\right)$ based on linkage disequilibrium. The lowest allele frequency was 0.02. n: harmonic mean of sample size (accounting for missing data). SNP: single nucleotide polymorphism. BCB: Bering/Chukchi/Beaufort Seas; EC: Eastern Canada; SO: Sea of Okhotsk

\begin{tabular}{|lcc|}
\hline Population (n) & $\begin{array}{c}N_{\mathrm{e}} \\
(95 \% \mathrm{CI})\end{array}$ & $\begin{array}{c}\text { No. independent } \\
\text { alleles }\end{array}$ \\
\hline 22 microsatellites & & \\
BCB (298) & $357(134-\infty)$ & 22743 \\
EC (46) & $214(124-655)$ & 20019 \\
SO (60) & $112(79-183)$ & 13156 \\
29 phased SNPs & & \\
BCB (409) & $1593(689-\infty)$ & 1172 \\
EC (48) & $238(90-\infty)$ & 1005 \\
SO (49) & $5828(165-\infty)$ & 1141 \\
29 SNPs and 22 microsatellites & \\
BCB (277) & $405(183-4001)$ & 33380 \\
SO (48) & $137(101-209)$ & 23922 \\
\hline
\end{tabular}

high, and estimates of $F_{\mathrm{ST}}$ remained consistent when sample sizes of 40 or 20 were used, though the smallest $F_{\mathrm{ST}}$ measure (between BCB and EC) was not significant with only 20 samples per population for both
SNPs and microsatellites (Table 5). There was no bias in the estimated $F_{\mathrm{ST}}$ value with smaller sample sizes, though the variance increased as expected (data not shown), reducing precision. We then randomly resampled 40 samples from each population and investigated power with 5 and 10 randomly selected genetic markers. With 10 loci, both SNPs and microsatellites continued to perform equally; with 5 loci, only the comparison using SNPs to detect the smallest $F_{\mathrm{ST}}$ value (BCB versus $\mathrm{EC}$ ) was non-significant, while it remained significant for 5 microsatellites (Table 5). Our results indicate that a reasonable number of samples (e.g. 40) and $\geq 10$ SNPs should be adequate for detection of population structure at these levels of differentiation.

Assignment of samples to their population of origin using the assignment test program GeneClass2 is shown in Table S2 in the Supplement at www.int-res. com/articles/suppl/n019p129_supp.xls. GeneClass2 considers self-assignment to be correct if the probability is $>50 \%$ (for 2 populations), but since assignment of unknown samples would be considered strongly supported only at a higher level, we also calculated the proportion of individuals correctly as-

Table 5. Pairwise $F_{\mathrm{ST}}\left(G^{\prime \prime}{ }_{\text {ST }}\right)$ below the diagonal and p-values above the diagonal for (A) all samples and all loci, (B) median of 1000 replicates of 40 random samples per population, (C) median of 1000 replicates of 20 random samples per population, (D) same as B, but with 10 loci chosen randomly for each replicate, and (E) with 5 loci chosen randomly for each replicate. Sample sizes are indicated in parentheses after the population names. The same samples were genotyped for the Bering/Chukchi/ Beaufort Seas (BCB) and the Sea of Okhotsk (SO) for both single nucleotide polymorphisms (SNPs) and microsatellites, but samples from Eastern Canada (EC) were non-overlapping, so different samples were used to calculate statistics for microsatellites versus SNPs. p-values were based on 500 permutations. Values in bold indicate significance at $\mathrm{p}<0.05$

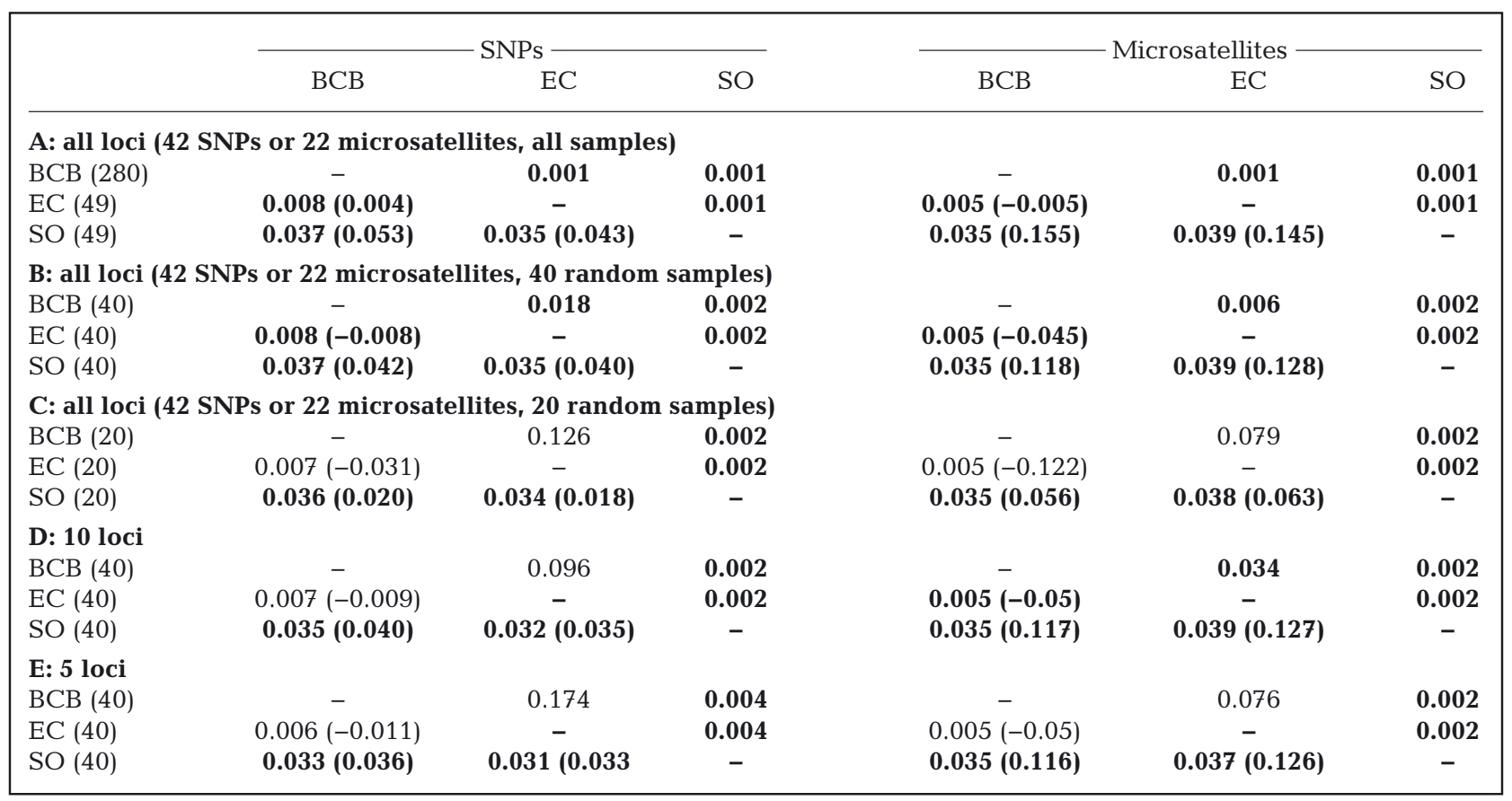


Table 6. Mean assignment of individuals from the 3 populations (Bering/ Chukchi/Beaufort Seas (BCB], Eastern Canada [EC], and Sea of Okhotsk [SO) to groups when STRUCTURE was used to define 3 groups $(k=3)$. Analyses were run using all single nucleotide polymorphism (SNP) markers, all (22) microsatellite markers (msats), or a randomly chosen subset of microsatellite markers. All analyses were run 10 times. In analyses where a subset of microsatellite markers was used, a different randomly chosen set of markers was used in each replicate. The USELOC parameter controls whether or not sampling location is used as a prior in the analysis (True $=$ used, False $=$ not used)

\begin{tabular}{|c|c|c|c|c|c|}
\hline \multirow[t]{2}{*}{ USELOC } & \multirow{2}{*}{$\begin{array}{c}\text { Markers } \\
\text { used }\end{array}$} & \multirow[t]{2}{*}{ Population } & \multicolumn{3}{|c|}{ — STRUCTURE group - } \\
\hline & & & 1 & 2 & 3 \\
\hline \multirow[t]{15}{*}{ False } & \multirow[t]{3}{*}{22 msats } & BCB & 0.485618 & 0.515062 & 0.032861 \\
\hline & & $\mathrm{EC}$ & 0.482087 & 0.453198 & 0.035427 \\
\hline & & $\mathrm{SO}$ & 0.032298 & 0.031811 & 0.931647 \\
\hline & \multirow[t]{3}{*}{15 msats } & $\mathrm{BCB}$ & 0.468911 & 0.44387 & 0.05621 \\
\hline & & $\mathrm{EC}$ & 0.4636 & 0.49033 & 0.060343 \\
\hline & & $\mathrm{SO}$ & 0.067472 & 0.065791 & 0.883445 \\
\hline & \multirow[t]{3}{*}{10 msats } & $\mathrm{BCB}$ & 0.42658 & 0.402079 & 0.07432 \\
\hline & & $\mathrm{EC}$ & 0.414357 & 0.436806 & 0.087465 \\
\hline & & $\mathrm{SO}$ & 0.159068 & 0.16114 & 0.838222 \\
\hline & \multirow[t]{3}{*}{5 msats } & $\mathrm{BCB}$ & 0.334964 & 0.329689 & 0.32871 \\
\hline & & $\mathrm{EC}$ & 0.33307 & 0.334206 & 0.333714 \\
\hline & & $\mathrm{SO}$ & 0.331966 & 0.336087 & 0.33762 \\
\hline & \multirow[t]{3}{*}{ SNPs } & $\mathrm{BCB}$ & 0.385495 & 0.288827 & 0.147302 \\
\hline & & $\mathrm{EC}$ & 0.337129 & 0.422343 & 0.210147 \\
\hline & & $\mathrm{SO}$ & 0.277362 & 0.288849 & 0.642555 \\
\hline \multirow[t]{15}{*}{ True } & \multirow[t]{3}{*}{22 msats } & $\mathrm{BCB}$ & 0.981256 & 0.32996 & 0.028124 \\
\hline & & $\mathrm{EC}$ & 0.015043 & 0.664172 & 0.006614 \\
\hline & & $\mathrm{SO}$ & 0.003737 & 0.005891 & 0.965263 \\
\hline & \multirow[t]{3}{*}{15 msats } & $\mathrm{BCB}$ & 0.984195 & 0.279291 & 0.039516 \\
\hline & & $\mathrm{EC}$ & 0.005907 & 0.701821 & 0.007916 \\
\hline & & $\mathrm{SO}$ & 0.009917 & 0.018913 & 0.952545 \\
\hline & \multirow[t]{3}{*}{10 msats } & $\mathrm{BCB}$ & 0.969562 & 0.247649 & 0.058404 \\
\hline & & $\mathrm{EC}$ & 0.009906 & 0.727294 & 0.01388 \\
\hline & & $\mathrm{SO}$ & 0.020523 & 0.025026 & 0.927694 \\
\hline & \multirow[t]{3}{*}{5 msats } & $\mathrm{BCB}$ & 0.734019 & 0.636036 & 0.028273 \\
\hline & & $\mathrm{EC}$ & 0.227746 & 0.32947 & 0.139339 \\
\hline & & $\mathrm{SO}$ & 0.038235 & 0.034485 & 0.832376 \\
\hline & \multirow[t]{3}{*}{ SNPs } & $\mathrm{BCB}$ & 0.846025 & 0.385153 & 0.086831 \\
\hline & & $\mathrm{EC}$ & 0.122126 & 0.581027 & 0.081516 \\
\hline & & $\mathrm{SO}$ & 0.031839 & 0.033839 & 0.831667 \\
\hline
\end{tabular}

When we used STRUCTURE to analyze data from all of the microsatellite markers and did not use sampling location as a prior, the model with the highest average ln $\mathrm{P}(\mathrm{D})$ was the one with 5 groups $(k=5)$, while $\Delta k$ was highest when $k=2$ (Table S3 in the supplement at www.int-res.com/articles /suppl/n019p129_supp.xls). It is worth noting, as observed in the previous analysis of the microsatellite data (Givens et al. 2010), that the authors of STRUCTURE indicated that the method for statistical inference for the number of populations $(k)$ tends to overestimate the likely value of $k$ (Pritchard et al. 2000), and $\Delta k$ is a better measure of the number of populations when $\ln \mathrm{P}(\mathrm{D})$ steadily increases with increasing $k$ (Evanno et al. 2005, but see Waples \& Gaggiotti 2006). Givens et al. (2010) also determined that $k=2$ best represented the microsatellite data from the 3 bowhead stocks (BCB, SO, and EC).

STRUCTURE was able to distinguish the SO population from a combined $\mathrm{BCB}$ and EC group, with mean assignment probabilities of approximately $96 \%$ of BCB and EC samples to one group and $96 \%$ of SO samples to the other group when $k=2$. When $k=3$, SO had a mean assignment probability of $93 \%$ to Group 3, while BCB and EC were both split nearly evenly between Groups 1 and 2, indicating that these 2 populations could not be distinguished signed when the probability was $>90 \%$. Our $22 \mathrm{mi}-$ crosatellites were able to correctly assign almost all samples (>98\%) under both criteria, but the 29 phased SNP loci correctly assigned only approximately 92 and $72 \%$ of the samples, respectively. When both marker types were combined, correct assignment increased to greater than $99 \%$ under both criteria. To see what portion of microsatellites would result in approximately the same assignment power as our 29 phased SNP loci, we randomly sub-sampled smaller numbers of microsatellites and performed the assignment of the same samples. Ten random samples of 5 of the 22 microsatellites resulted in a mean of $90.4 \%$ (range $86.4-95.2 \%$ ) of samples assigned correctly with $\geq 50 \%$ probability, and a mean of $74.1 \%$ (60.3-88.5\%) assigned with $\geq 90 \%$ probability.
(Table 6). When we analyzed the SNP data without using sampling location as a prior, the average $\ln$ $\mathrm{P}(\mathrm{D})$ was maximized when $k=1$, while $\Delta k$ was highassigned nearly equally to both groups, while SO had a $62.7 \%$ mean assignment probability to one of the groups. When $k=3$, SO had $64.3 \%$ assignment to Group 3, while the assignments for BCB and EC were spread across all 3 groups (Table 6).

The model containing 2 groups $(k=2)$ had the highest $\ln \mathrm{P}(\mathrm{D})$ and highest $\Delta k$ in both data sets when sampling location was used as a prior. With the microsatellite data set and $k=2, \mathrm{BCB}$ and EC had mean assignment probabilities to Group 1 of over $99 \%$, while SO had a $97.7 \%$ mean assignment to Group 2. With SNPs, BCB and EC had mean assignest for $k=3$ (Table S3). When $k=2$, BCB and EC 
ments to Group 1 of 96 and $85.6 \%$, respectively, while SO had a mean assignment to Group 2 of $89.5 \%$. Inclusion of sampling location as a prior improved the ability of STRUCTURE to separate BCB and EC. When the model with 3 groups $(k=3)$ was evaluated with the microsatellite data set, the $\mathrm{BCB}$ samples assigned predominantly to Group $1(98.1 \%)$, EC to Group 2 (66.4\%), and SO to Group $3(96.5 \%)$ (Table 6). The 3 populations were also identified in the SNP data set, though mean assignments to their respective groups were lower $(\mathrm{BCB}=84.6 \%, \mathrm{EC}=$ $58.1 \%$, SO $=83.2 \%$; Table 6 )

When sampling location was not used as a prior, increasing the number of microsatellite markers resulted in a steady increase in the method's ability to distinguish SO from $\mathrm{BCB}$ and $\mathrm{EC}$, with results ranging from no ability to distinguish populations with 5 markers to near perfect separation with 22 markers (Fig. 2, Table 6). When sampling location was used as a prior, changing the number of microsatellites had little effect, as all subsets of markers resulted in correct assignment. Regardless of the use of sampling location, the performance of the method with the full SNP data set was intermediate compared with the performance with 5 and 10 microsatellites (Table 6).

\section{DISCUSSION}

This study represents a thorough comparison of the use of SNPs versus microsatellites and mitochondrial DNA to detect low-level population structure in bowhead whales, with a focus on establishing baseline data for monitoring after significant demographic changes due to historical whaling, and in the face of climate change. We have used a combination of 42 linked and unlinked SNPs, inferred the phased haplotypes of linked SNPs, and then compared the resulting 29 phased SNP locus data set directly with results obtained using 22 highly polymorphic microsatellites.

We expected that microsatellites would provide higher power to detect population differences because they have a much larger number of independent alleles (Kalinowski 2002), but simulations indicated that even this relatively small number of independent SNP loci should provide sufficient power to detect fine-scale population structure (Morin et al. 2009c). Detection of genetic structure depends on several factors, including number and type of genetic loci, number of samples from each population, and the level of differentiation, which is

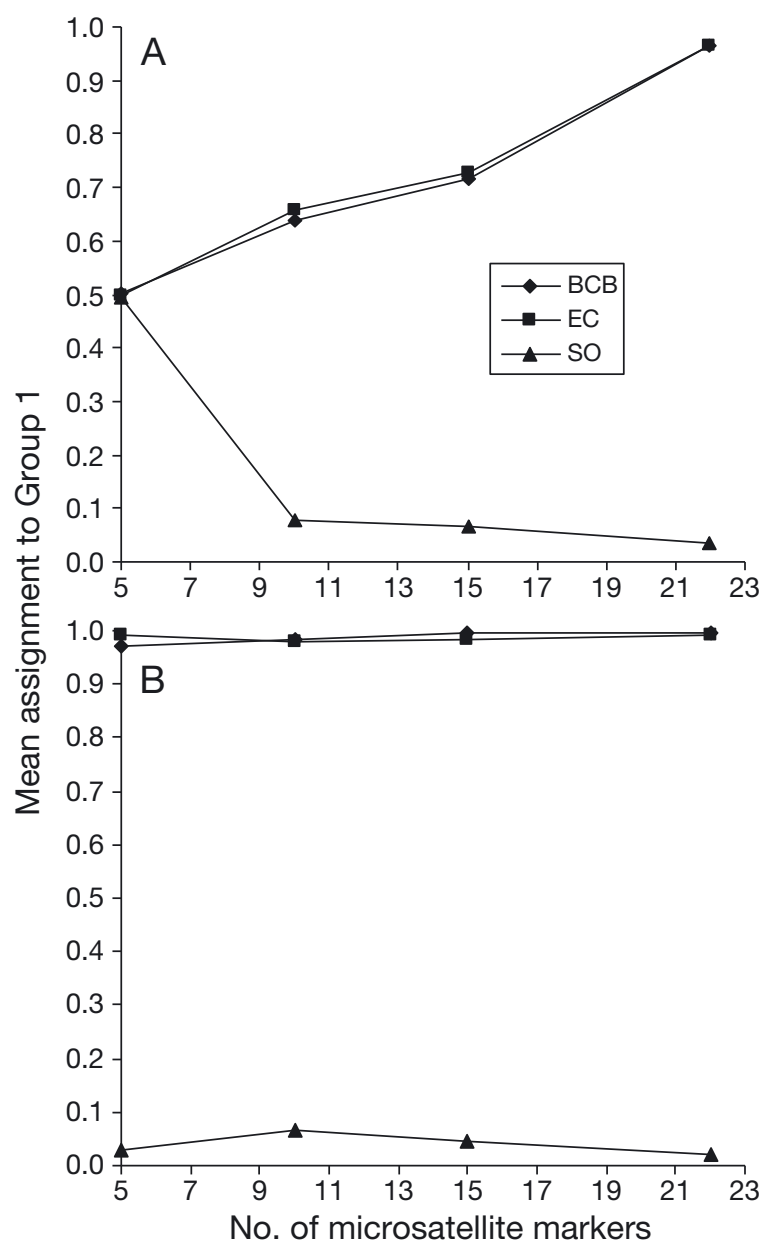

Fig. 2. Mean assignment of individuals to Group 1 as a function of the number of microsatellite markers included in the analysis when STRUCTURE is used to define 2 groups (arbitrarily designated Group 1 and Group 2). Results are shown for analyses (A) in which sampling location is not used as a prior, and (B) when it is used as a prior. All analyses were run 10 times. In analyses where a subset of microsatellite markers was used, a different randomly chosen set of markers was used in each replicate. BCB: Bering/Chukchi/

Beaufort Seas; EC: Eastern Canada; SO: Sea of Okhotsk

in turn dependent on $N_{\mathrm{e}}$, generation time, and dispersal rate. We have used comparison of SNP and microsatellite data for detecting different levels of population structure, and for estimation of $N_{\mathrm{e}}$, to further test the use of SNPs as efficient and effective population genetic markers.

\section{Population structure in bowhead whales}

Our results confirmed that SNP analysis detected significant geographic genetic differences among bowhead whale populations, even when $F_{\mathrm{ST}}<0.01$. 
This low level of differentiation between the BCB and EC populations results from relatively high abundance coupled with demographically trivial dispersal rates (roughly 0.7 individuals per year, which for a population of 10000 would be $0.007 \%$ per year). The estimated level of gene flow between BCB and EC bowhead populations is consistent with these 2 populations breeding in different ocean basins but having had historically sporadic gene flow, and the species having a very long generation time. Despite the low level of differentiation between the BCB and EC populations, SNPs proved surprisingly powerful for detecting population differences between these demographically independent populations even with reduced sample sizes (see next section).

Our analysis of age cohorts necessarily used smaller sample sizes, with the oldest cohort numbering only 5 and 7 for microsatellites and SNPs, respectively. With these small sample sizes, SNPs were unable to detect the significant differences found with mtDNA and microsatellites, highlighting again the important relationship between sample number and number of markers (or alleles) (Krawczak 1999, Kalinowski 2002, Morin et al. 2009c), as well as potential effects of smaller marker $N_{\mathrm{e}}$ (mtDNA) and higher mutation rates (mtDNA and microsatellites). In this case, where addition of samples is unlikely, use of microsatellites or more SNPs is warranted. One way to increase the sample size for these old animals is to use historical samples (bone and baleen) if age can be estimated from museum records. Such samples can be genotyped with SNPs with high accuracy (Morin \& McCarthy 2007), but not with microsatellites.

\section{Number of markers for detecting structure and population assignment}

It has previously been suggested that $\geq 10$ times more SNPs might be needed to match the power of microsatellites for some applications such as detecting population structure (Kalinowski 2002). Subsequent studies have indicated that fewer SNPs are needed, based on either simulated data (Morin et al. 2009c) or empirical data (e.g. Ryynänen et al. 2007, Narum et al. 2008, Smith \& Seeb 2008, Coates et al. 2009). In all of these latter cases, a given number of SNPs were compared with a set of microsatellites to determine whether SNPs performed similarly to microsatellites for one or more analyses (e.g. $F_{\mathrm{ST}}$ or assignment). As in several of those studies, we obtained nearly identical $F_{\text {ST }}$ values and statistical significance with our 2 sets of markers, but then went on to evaluate how the use of fewer markers or samples randomly selected from our set would perform (rather than based on information content for differentiating samples from specific populations). The results were surprising for some analyses. For divergence $\left(F_{\mathrm{ST}}\right)$, as few as 10 SNPs or microsatellites (with 40 samples per population) were roughly equal in detecting significant divergence between populations with $F_{\text {ST }}$ values ranging from 0.005 to 0.04 (Table 6). This was true both for the comparison of 2 large and similarly sized populations (BCB and $\mathrm{EC}$ ), and for the comparison of the large populations and the small population (SO).

The ability to assign individuals to a given population is particularly useful when organisms are migratory or mix at times during their annual or life cycle. Assignment using SNPs has been evaluated extensively for mixed-stock analysis of salmonids (e.g. Narum et al. 2008, Smith \& Seeb 2008), where markers are selected to maximize assignment probability to a set of well-characterized populations. When the number of markers is limiting (as it may be for some time in most species with little genomic information or economic importance), assignment probability must be assessed with the markers available. Our results from the program GeneClass2 indicate that our set of 29 multi-allelic and bi-allelic SNP loci performed nearly as well as 22 microsatellites when the assignment criterion was $50 \%$, but performed less well when the assignment criterion was $90 \%$. Nevertheless, these results are encouraging for the use of randomly selected SNPs for assignment tests, as even with the more stringent $90 \%$ assignment criterion nearly three-quarters of the samples were still assigned correctly to their population of origin for 2 populations with a divergence level of $F_{\mathrm{ST}}<0.04$. Improved assignment probability can be achieved by adding SNPs and/or increasing the reference population sample sizes. If assignment tests are the primary objective of a study, however, high probabilities of assignment can be achieved with relatively few microsatellites, but larger numbers of SNPs or highly diagnostic SNPs have also been selected and shown to outperform microsatellites when the SNPs can be pre-selected for assignment to known populations (e.g. Lao et al. 2006, Paschou et al. 2007, Smith \& Seeb 2008). It is likely that bowhead whales will start moving between the eastern and western Arctic via the Northwest Passage in the near future as climate change causes decreasing ice coverage. If it becomes important to assign individuals to stock of origin, the current SNP data set could be supplemented with additional SNPs to improve assignment probability. 


\section{Bayesian population inference}

A method that is commonly used in population structure studies is inference of structure and assignment of individuals to putative populations without a priori stratification of samples, using the Bayesian program STRUCTURE. This program is known to have limited power to detect differentiation of populations when the level of divergence is low (Hubisz et al. 2009). We did replicate analyses to determine the most probable number of populations inferred by STRUCTURE from SNP and microsatellite data, and found that in the absence of locality information used as a prior, neither marker type was able to correctly determine the number of populations or assign samples to the 2 most similar populations (BCB and EC). These results are consistent with those found by Givens et al. (2010) for the microsatellite data. Both marker types correctly assigned samples to the small SO population most of the time, but the rate of correct assignment was $96 \%$ with 22 microsatellites and only $63 \%$ with 29 phased SNP loci. Adding locality information significantly improved the ability to detect both the number of populations and to correctly assign individuals. However, the ability to correctly assign individuals using SNPs was consistently lower than that achieved using approximately 5 to 10 microsatellites, indicating that more SNPs will be needed for Bayesian assignment using STRUCTURE and that fewer microsatellites could perform equally as well. For both marker types, STRUCTURE was able to differentiate a small population compared with a large one but was unable to detect the presence of 2 separate large populations with very little if any current gene flow. Given the highly significant differences using frequency statistics ( $p=0.001$; Table 3 ) and low estimated annual dispersal (roughly 0.7 individuals each year) between these populations, this empirical case provides strong evidence that negative results from STRUCTURE (i.e. no indication that the BCB and EC are separate populations) should not be used as evidence against demographic independence of relatively abundant populations.

\section{Demographic analyses}

Previous studies with microsatellites and mtDNA have failed to detect evidence of a genetic bottleneck (Rooney et al. 1999, 2001, Givens et al. 2010). Although it would have been interesting to compare the power of SNPs and microsatellites to detect a bottleneck, the available methods rely on detection of excess of heterozygosity that would be affected by the ascertainment methods. Given that most SNP ascertainment methods will have some ascertainment bias, especially when the ascertainment sample size is limited or when low-frequency SNPs are excluded, these methods will be biased to indicate a bottleneck even when one has not occurred (G. Luikart, A. Gonçalves da Silva, pers. comm.). This leaves us with only the option of inferring changes in effective population size relative to a historical estimate (if that can be known).

Our results indicate that SNPs are likely to have much greater variance in estimates of $N_{\mathrm{e}}$ due to the lower number of pairwise allelic linkage disequilibrium comparisons (Table 4). Based on simulated data, Waples \& Do (2010) suggested that approximately 180 SNPs would be needed to match the same level of precision as 20 microsatellites with 10 alleles each. However, Antao et al. (2011) have recently shown that increasing the number of sampled individuals is more beneficial than increasing the number of loci for 2 methods of estimating $N_{\text {e, }}$ and that 40 SNPs gave only slightly lower precision than 10 microsatellites.

Our estimates of $N_{\mathrm{e}}$ from SNPs, and to some extent microsatellites, had wide confidence intervals. Microsatellite-based estimates were in the low hundreds of individuals, possibly reflecting the recent ( $<2$ generations) population bottleneck and long generation time of bowhead whales. SNP estimates all ranged to infinity, and the point estimates for both $\mathrm{BCB}$ and SO were in the thousands, though the confidence intervals substantially overlapped those from microsatellites. The population size estimate of 5728 from our 29 phased SNP loci was especially high for the SO population, which is believed to contain only a few hundred animals and is estimated to have had a total population size (N) of 3000-6500 animals $\left(N_{\mathrm{e}} \sim\right.$ 1950-4225) prior to commercial whaling (Woodby \& Bodkin 1993). This could reflect the fact that this population has not recovered like the other populations, and may contain a larger portion of adults that represent the pre-exploitation population, but why the estimate differs so strongly from that obtained from microsatellite data is unclear. Indeed, when SNP and microsatellite data were combined, the estimates converged much more closely to those from microsatellites alone, and confidence intervals narrowed, indicating that it is likely the high 'noise' in the SNP estimates that caused the anomylous estimates of $N_{\mathrm{e}}$ rather than an inherent bias in the estimates based on SNPs. 
All estimates of $N_{\mathrm{e}}$ are likely to be affected by violations of the assumptions of equilibrium (Archer et al. 2010), non-overlapping generations, and random sampling with respect to relatedness. Overlapping generations would likely tend to affect the $N_{\mathrm{e}}$ estimate (up or down depending on species life history and sampling strategy) because the model assumes only one generation in a cohort, and the estimate may be increased by the larger total number of parents in multi-generation sampling or decreased due to nonrandom sampling of family cohorts (Waples 2006, R. S. Waples pers. comm). The $N_{\mathrm{e}} / \mathrm{N}$ ratio could be higher than would be expected for a population in equilibrium in the case of a population recovering from severe depletion coupled with a high longevity such that some living individuals were born prior to the bottleneck. Our results support the need for more performance testing of available methods to explore the expected results of using different types of genetic markers.

\section{CONCLUSIONS}

Some other advantages of SNPs should be considered when selecting markers. One is the type of samples that are likely to be available for genotyping. SNPs can be used to accurately genotype samples of very poor quality, such as historical and noninvasive samples (Morin \& McCarthy 2007). In this study of bowhead whales, we were able to add 49 historical samples to one of our strata from a poorly represented geographic area. A second consideration is the likely need to add data to the study in the future, or to merge data from researchers in other laboratories for combined analysis. Microsatellite genotypes have proven difficult to replicate over space and time (LaHood et al. 2002, Davison \& Chiba 2003, Amos et al. 2007, Morin et al. 2009b). In contrast, SNP genotypes are less technology dependent because they represent differences between discrete nucleotides (G, A, T, and C), not estimated allele sizes, and can easily be combined from different data sets for analysis without the need for calibration.

This comparative study illustrates that for detecting and monitoring bowhead populations, SNPs provide similar power to microsatellites for all analyses except those with very small sample sizes, and offer the additional benefits of cost-effective genotyping methods, the ability to genotype poor-quality and historical samples, and ease of combining data generated over time with changing technologies and in different laboratories. With SNPs, ancestral states of alleles can be known (e.g. by genotyping individuals of related species) for inference of derived alleles in evolutionary studies. Interpretation of population genetic analytical methods is also more straightforward, as traditional $F_{\mathrm{ST}}$ measures of differentiation can be used without the need to infer mutation rates and models, or to correct for high levels of heterozygosity. Although microsatellites will remain an important tool for many population studies, SNPs are continuing to prove to be viable, and in some cases superior, tools for understanding structure and demography of populations.

Acknowledgements. We are grateful to the Southwest Fisheries Science Center, the North Pacific Research Board (publication 361), and the North Slope Borough for support of this research. BCB bowhead whale DNA samples for genotyping were supplied by The North Slope Borough, and we thank the whaling captains, their crew, and the Eskimo villages that provided invaluable samples, as well as Dave Withrow (National Marine Mammal Lab, NOAA Alaska Fisheries Science Center) and Bob Brownell (SWFSC). Museum samples were generously provided by Jim Dines and the Los Angeles County Museum of Natural History. We are grateful to Vicki Pease, Brittany Hancock-Hanser, Kelly Robertson, Amy van Cise, and Caroline Antolik for assistance in generating SNP genotype data, and to Rich Cosgrove for preparing sample map figures. Valuable discussion on earlier versions of the manuscript was provided by Kim Parsons, Robin Waples, Bill Perrin, and 5 anonymous reviewers.

\section{LITERATURE CITED}

Amend A, Garbelotto M, Fang ZD, Keeley S (2010) Isolation by landscape in populations of a prized edible mushroom Tricholoma matsutake. Conserv Genet 11:795-802

Amos W (1997) Marine mammal tissue sample collection and preservation for genetic analyses. In: Dizon AE, Chivers SJ, Perrin WF (eds) Molecular genetics of marine mammals. Special Publication 3, Society for Marine Mammalogy, Lawrence, KS, p 107-113

Amos W, Hoffman JI, Frodsham A, Zhang L, Best S, Hill VS (2007) Automated binning of microsatellite alleles: problems and solutions. Mol Ecol Notes 7:10-14

Antao T, Perez-Figueroa A, Luikart G (2011) Early detection of population declines: high power of genetic monitoring using effective population size estimators. Evol Appl 4: 144-154

Archer FI, Martien KK, Taylor BL, LeDuc RG, Ripley BJ, Givens GH, George JC (2010) A simulation-based approach to evaluating population structure in non-equilibrial populations. J Cetacean Res Manag 11:101-113

Balloux F, Lugon-Moulin N (2002) The estimation of population differentiation with microsatellite markers. Mol Ecol 11:155-165

Berlin S, Quintela M, Hoglund J (2008) A multilocus assay reveals high nucleotide diversity and limited differentiation among Scandinavian willow grouse (Lagopus lagopus). BMC Genet 9:89 
Brandon JR, Wade PR (2006) Assessment of the BeringChukchi-Beaufort Seas stock of bowhead whales using Bayesian model averaging. J Cetacean Res Manag 8: 225-239

> Brumfield RT, Beerli P, Nickerson DA, Edwards SV (2003) The utility of single nucleotide polymorphisms in inferences of population history. Trends Ecol Evol 18:249-255

Burns JJ, Montague JJ, Cowles C (eds) (1993) The bowhead whale. Society for Marine Mammology, Lawrence, KS

Coates BS, Sumerford DV, Miller NJ, Kim KS, Sappington TW, Siegfried BD, Lewis LC (2009) Comparative performance of single nucleotide polymorphism and microsatellite markers for population genetic analysis. J Hered 100:556-564

> Davison A, Chiba S (2003) Laboratory temperature variation is a previously unrecognized source of genotyping error during capillary electrophoresis. Mol Ecol Notes 3: 321-323

Dyke AS, Hooper J, Savelle JM (1996) A history of sea ice in the Canadian Arctic Archipelago based on postglacial remains of the bowhead whale (Balaena mysticetus). Arctic 49:235-255

Evanno G, Regnaut S, Goudet J (2005) Detecting the number of clusters of individuals using the software STRUCTURE: a simulation study. Mol Ecol 14:2611-2620

Falush D, Stephens M, Pritchard JK (2003) Inference of population structure using multilocus genotype data: linked loci and correlated allele frequencies. Genetics 164: 1567-1587

Finley KJ (2001) Natural history and conservation of the Greenland whale, or bowhead, in the northwest Atlantic. Arctic 54:55-76

Foll M, Gaggiotti O (2008) A genome-scan method to identify selected loci appropriate for both dominant and codominant markers: a Bayesian perspective. Genetics 180:977-993

Freamo H, O'Reilly P, Berg PR, Lien S, Boulding EG (2011) Outlier SNPs show more genetic structure between two Bay of Fundy metapopulations of Atlantic salmon than do neutral SNPs. Mol Ecol Resour 11(Suppl 1):254-267

- Gemmell NJ, Akiyama S (1996) An efficient method for the extraction of DNA from vertebrate tissues. Trends Genet 12:338-339

George JC, Bada J, Zeh JE, Scott L, Brown SE, O'Hara T, Suydam RS (1999) Age and growth estimates of bowhead whales (Balaena mysticetus) via aspartic acid racemization. Can J Zool 77:571-580

> George JC, Zeh JE, Suydam RS, Clark C (2004) Abundance and population trend (1978-2001) of western Arctic bowhead whales (Balaena mysticetus) surveyed near Barrow, Alaska. Mar Mamm Sci 20:755-773

Givens GH, Huebinger RM, Patton JC, Postma LD, and others (2010) Population genetics of bowhead whales (Balaena mysticetus) in the western Arctic. Arctic 63:1-12

Glover KA, Hansen MM, Lien S, Als TD, Hoyheim B, Skaala O (2010) A comparison of SNP and STR loci for delineating population structure and performing individual genetic assignment. BMC Genet 11:2

Hedrick PW (2005) A standardized genetic differentiation measure. Evolution 59:1633-1638

> Hefti-Gautschi B, Pfunder M, Jenni L, Keller V, Ellegren H (2009) Identification of conservation units in the European Mergus merganser based on nuclear and mitochondrial DNA markers. Conserv Genet 10:87-99

Heide-Jørgensen MP, Laidre KL, Fossette S (2006a) Re- analysis of a re-analysis of a Canadian bowhead survey. Report No. SC/60/BRG21, International Whaling Commission annual meeting, Saint Kitts and Nevis, West Indies. IWC, Cambridge

Heide-Jørgensen MP, Laidre KL, Jensen MV, Dueck L, Postma LD (2006b) Dissolving stock discreteness with satellite tracking: bowhead whales in Baffin Bay. Mar Mamm Sci 22:34-45

> Heller R, Siegismund HR (2009) Relationship between three measures of genetic differentiation $\mathrm{G}(\mathrm{ST}), \mathrm{D}(\mathrm{EST})$ and $\mathrm{G}^{\prime}(\mathrm{ST})$ : how wrong have we been? Mol Ecol 18: 2080-2083, discussion 2088-2091

- Helyar SJ, Hemmer-Hansen J, Bekkevold D, Taylor MI, and others (2011) Application of SNPs for population genetics of nonmodel organisms: new opportunities and challenges. Mol Ecol Resour 11(Suppl 1):123-136

> Hess JE, Matala AP, Narum SR (2011) Comparison of SNPs and microsatellites for fine-scale application of genetic stock identification of Chinook salmon in the Columbia River Basin. Mol Ecol Resour 11(Suppl 1):137-149

Hubisz MJ, Falush D, Stephens M, Pritchard JK (2009) Inferring weak population structure with the assistance of sample group information. Mol Ecol Resour 9:1322-1332

Jorde PE, Schweder T, Bickham JW, Givens GH, Suydam R, Hunter D, Stenseth NC (2007) Detecting genetic structure in migrating bowhead whales off the coast of Barrow, Alaska. Mol Ecol 16:1993-2004

Jost L (2009) $D$ vs. $G_{\mathrm{ST}}$ : response to Heller and Siegismund (2009) and Ryman and Leimar (2009). Mol Ecol 18: 2088-2091

Kalinowski ST (2002) How many alleles per locus should be used to estimate genetic distances? Heredity 88:62-65

Keller SR, Olson MS, Silim S, Schroeder W, Tiffin P (2010) Genomic diversity, population structure, and migration following rapid range expansion in the Balsam poplar, Populus balsamifera. Mol Ecol 19:1212-1226

Krawczak M (1999) Informativity assessment for biallelic single nucleotide polymorphisms. Electrophoresis 20: 1676-1681

Krutzikowsky GK, Mate BR (2000) Dive and surfacing characteristics of bowhead whales (Balaena mysticetus) in the Beaufort and Chukchi Seas. Can J Zool 78:1182-1198

> LaHood ES, Moran P, Olsen J, Grant WS, Park LK (2002) Microsatellite allele ladders in two species of Pacific salmon: preparation and field-test results. Mol Ecol Notes 2:187-190

> Lao O, van Duijn K, Kersbergen P, de Knijff P, Kayser M (2006) Proportioning whole-genome single-nucleotidepolymorphism diversity for the identification of geographic population structure and genetic ancestry. Am J Hum Genet 78:680-690

LeDuc RG, Dizon AE, Burdin AM, Blokhin SA, George JC, Brownell RL Jr (2005) Genetic analysis (mtDNA and microsatellites) of Okhotsk and Bering/Chukchi/Beaufort Seas populations of bowhead whales. J Cetacean Res Manag 7:107-111

LeDuc RG, Martien KK, Morin PA, Hedrick NM, and others (2008) Mitochondrial genetic variation in bowhead whales in the western Arctic. J Cetacean Res Manag 10: 93-97

Lubetkin SC, Zeh JE (2006) Deriving age-length relationships for bowhead whales (Balaena mysticetus) using a synthesis of age estimation techniques. Report No. SC/58/BRG14, International Whaling Commission, Anchorage, AK 
Lubetkin SC, Zeh JE, Rosa C, George JC (2008) Age estimation for young bowhead whales (Balaena mysticetus) using annual baleen growth increments. Can J Zool 86: 525-538

> McKelvey KS, Schwartz MK (2004) Genetic errors associated with population estimation using non-invasive molecular tagging: problems and new solutions. J Wildl Manag 68:439-448

McLeod SA, Whitmore FC Jr, Barnes LG (1993) Evolutionary relationships and classification. In: Burns JJ, Montague JJ, Cowles CJ (eds) The bowhead whale. Society for Marine Mammalogy, Lawrence, KS, p 45-70

> Meirmans PG, Hedrick PW (2011) Assessing population structure: $F_{\mathrm{ST}}$ and related measures. Mol Ecol Res 11: 5-18

> Mesnick S, Taylor B, Archer EI, Martien K, and others (2011) Sperm whale population structure in the eastern North Pacific inferred by the use of single nucleotide polymorphisms (SNPs), microsatellites and mitochondrial DNA. Mol Ecol Res 11(Suppl 1):278-298

Miller SA, Dykes DD, Polesky HF (1988) A simple salting out procedure for extracting DNA from human nucleated cells. Nucleic Acids Res 16:1215

Mims MC, Hulsey CD, Fitzpatrick BM, Streelman JT (2010) Geography disentangles introgression from ancestral polymorphism in Lake Malawi cichlids. Mol Ecol 19: 940-951

> Morin PA, McCarthy M (2007) Highly accurate SNP genotyping from historical and low-quality samples. Mol Ecol Notes 7:937-946

Morin PA, Chambers KE, Boesch C, Vigilant L (2001) Quantitative polymerase chain reaction analysis of DNA from noninvasive samples for accurate microsatellite genotyping of wild chimpanzees (Pan troglodytes verus). Mol Ecol 10:1835-1844

Morin PA, Luikart G, Wayne RK, SNP Workshop Group (2004) SNPs in ecology, evolution and conservation. Trends Ecol Evol 19:208-216

Morin PA, LeDuc RG, Robertson KM, Hedrick NM and others (2006) Genetic analysis of killer whale (Orcinus orca) historical bone and tooth samples to identify western U.S. ecotypes. Mar Mamm Sci 22:897-909

> Morin PA, Hedrick NM, Robertson KM, LeDuc CA (2007) Comparative mitochondrial and nuclear quantitative PCR of historical marine mammal tissue, bone, baleen, and tooth samples. Mol Ecol Notes 7:404-411

> Morin PA, LeDuc RG, Archer FI, Martien KK, Huebinger R, Bickham JW, Taylor BL (2009a) Significant deviations from Hardy-Weinberg equilibrium caused by low levels of microsatellite genotyping errors. Mol Ecol Resour 9: 498-504

Morin PA, Manaster C, Mesnick SL, Holland R (2009b) Normalization and binning of historical and multi-source microsatellite data: overcoming the problems of allele size shift with ALLELOGRAM. Mol Ecol Resour 9:1451-1455

> Morin PA, Martien KK, Taylor BL (2009c) Assessing statistical power of SNPs for population structure and conservation studies. Mol Ecol Resour 9:66-73

Morin PA, Pease VL, Hancock BL, Robertson KM, Antolik CW, Huebinger RM (2010) Characterization of 42 SNP markers for the bowhead whale (Balaena mysticetus) for use in discriminating populations. Mar Mamm Sci 26: 716-732

Narum SR, Banks M, Beacham TD, Bellinger MR and others (2008) Differentiating salmon populations at broad and fine geographical scales with microsatellites and single nucleotide polymorphisms. Mol Ecol 17:3464-3477

Noongwook G, Huntington HP, George JC, Savoonga NV, Gambell NV (2007) Traditional knowledge of the bowhead whale (Balaena mysticetus) around St. Lawrence Island, Alaska. Arctic 60:47-54

Paschou P, Ziv E, Burchard EG, Choudhry S, RodriguezCintron W, Mahoney MW, Drineas P (2007) PCAcorrelated SNPs for structure identification in worldwide human populations. PLoS Genet 3:1e160

Piry S, Alapetite A, Cornuet J, Paetkau D, Baudouin L, Estoup A (2004) GENECLASS2: a software for genetic assignment and first-generation migrant detection. J Hered 95:536-539

> Pritchard JK, Stephens M, Donnelly P (2000) Inference of population structure using multilocus genotype data. Genetics 155:945-959

> Quintela M, Berlin S, Wang BA, Hoglund J (2010) Genetic diversity and differentiation among Lagopus lagopus populations in Scandinavia and Scotland: evolutionary significant units confirmed by SNP markers. Mol Ecol 19: 2380-2393

- Rannala B, Mountain JL (1997) Detecting immigration by using multilocus genotypes. Proc Natl Acad Sci USA 94: 9197-9201

R Development Core Team (2011) R: A language and environment for statistical computing. $\mathrm{R}$ Foundation for Statistical Computing, Vienna

Rooney AP, Honeycutt RL, Davis SK, Derr JN (1999) Evaluating a putative bottleneck in a population of bowhead whales from patterns of microsatellite diversity and genetic disequilibria. J Mol Evol 49:682-690

Rooney AP, Honeycutt RL, Derr JN (2001) Historical population size change of bowhead whales inferred from DNA sequence polymorphism data. Evolution 55:1678-1685

Rousset F (2008) genepop'007: a complete re-implementation of the genepop software for Windows and Linux. Mol Ecol Resour 8:103-106

Rugh D, DeMaster D, Rooney A, Breiwick J, Shelden K, Moore S (2003) A review of bowhead whale (Balaena mysticetus) stock identity. J Cetacean Res Manag 5: 267-279

Ryman N, Leimar O (2009) G(ST) is still a useful measure of genetic differentiation - a comment on Jost's D. Mol Ecol 18:2084-2087

> Ryynänen HJ, Tonteri A, Vasemägi A, Primmer CR (2007) A comparison of biallelic markers and microsatellites for the estimation of population and conservation genetic parameters in Atlantic salmon (Salmo salar). J Hered 98: 692-704

> Seddon JM, Parker HG, Ostrander EA, Ellegren H (2005) SNPs in ecological and conservation studies: a test in the Scandinavian wolf population. Mol Ecol 14:503-511

Seeb JE, Carvalho G, Hauser L, Naish K, Roberts S, Seeb LW (2011) Single-nucleotide polymorphism (SNP) discovery and applications of SNP genotyping in nonmodel organisms. Mol Ecol Resour 11:1-8

Smith CT, Seeb LW (2008) Number of alleles as a predictor of the relative assignment accuracy of STR and SNP baselines for chum salmon. Trans Am Fish Soc 137: 751-762

Stephens M, Smith NJ, Donnelly P (2001) A new statistical method for haplotype reconstruction from population data. Am J Hum Genet 68:978-989

Taylor BL (1997) Defining 'population' to meet management 
objectives for marine mammals. In: Dizon AE, Chivers SJ, Perrin WF (eds) Molecular genetics of marine mammals. Special Publication 3, Society for Marine Mammalogy, Lawrence, KS, p 49-66

Taylor BL, Chivers SJ, Larese J, Perrin WF (2007) Generation length and percent mature estimates for IUCN assessments of cetaceans. Report No. LJ-07-01, Southwest Fisheries Science Center, La Jolla, CA

Waples RS (2006) A bias correction for estimates of effective population size based on linkage disequilibrium at unlinked gene loci. Conserv Genet 7:167-184

> Waples RS, Do C (2008) LDNE: a program for estimating effective population size from data on linkage disequilibrium. Mol Ecol Resour 8:753-756

Editorial responsibility: Mike Bruford,

Cardiff, UK
Waples RS, Do C (2010) Linkage disequilibrium estimates of contemporary Ne using highly variable genetic markers: a largely untapped resource for applied conservation and evolution. Evol Appl 3:244-262

Waples RS, Gaggiotti O (2006) What is a population? An empirical evaluation of some genetic methods for identifying the number of gene pools and their degree of connectivity. Mol Ecol 15:1419-1439

Woodby DA, Bodkin DB (1993) Stock sizes prior to commercial whaling. In: Burns JJ, Montague JJ, Cowles C (eds) The bowhead whale. Society for Marine Mammalogy, Lawrence, KS, p 387-407

Wright S (1931) Evolution in Mendelian populations. Genetics 16:97-159

Submitted: May 30, 2011; Accepted: August 28, 2012 Proofs received from author(s): November 21, 2012 